\title{
Screening for Driver Disorientation at the Iowa Department of Transportation, Motor Vehicle Division
}

\author{
Sarah Andrade ${ }^{1}$, Linda Hill ${ }^{1}$, and Kim Snook ${ }^{2 a}$ \\ ${ }^{1}$ University of California San Diego, Department of Family Medicine and Public Health \\ ${ }^{2}$ Iowa Motor Vehicle Division, Office of Driver Services \\ ${ }^{a}$ Clearinghouse for Older Road User Safety
}

\begin{abstract}
Background and Purpose: Aging is associated with cognitive impairment, which interferes with safe driving ability. Cognitively-impaired drivers may present as confused and belligerent, creating challenges in differentiating these drivers from intoxicated or metabolically-impaired drivers. The Driver Orientation Screen for Cognitive Impairment (DOSCI) was developed to assist identification of disorientation and was piloted in the Iowa Department of Transportation. This study examined the feasibility, acceptability, and usefulness of the DOSCI at licensing agency offices, and to investigate the association between DOSCI performance and driver licensing outcomes. Methods: A sample of 2,510 DOSCI screens from 2,399 individuals was assessed. Data included the acceptability of the DOSCI among staff and clients, time to complete assessments, DOSCI outcomes, and final driver license status. Results: On a 5-point scale, mean score was $4.76(\mathrm{SD}=0.67)$ for Ease of Administration, $4.67(\mathrm{SD}=0.80)$ for Acceptance by Client, and 3.81 $(\mathrm{SD}=1.57)$ for Useful in Assessment. Clients who failed the assessment had significantly higher odds of not receiving a driver's license than clients who passed $(\mathrm{OR}=2.556)$. Conclusion: The DOSCI was quick to administer, well-accepted, and was associated with licensing outcome. The tool has potential to contribute to traffic injury prevention by identifying potentially impaired drivers requiring closer examination in a licensing agency setting.
\end{abstract}

(C) 2019 Californian Journal of Health Promotion. All rights reserved.

Keywords: Medically-impaired drivers; driver licensing outcomes; cognitive impairment; driving fitness; licensing agency screening

\section{Introduction}

Older adults, 65 and over, are the fastest growing population group in the United States (Ortman, Velkoff, \& Hogan, 2014). Many older adults begin to experience declines in health and functional ability as they age as well as increases in medication usage and frailty (Centers for Disease Control and Prevention, 2013). Approximately 2.2 million adults over 80 have permanent visual impairment (Congdon et al., 2004), $50 \%$ of adults over 75 have disabling hearing loss (National Institute on Deafness and Other Communication Disorders, 2015), and $34.5 \%$ of adults over 85 have clinically diagnosed dementia (Lindsay, Sykes, McDowell, Verreault, \& Laurin, 2004). Alzheimer's disease is one of the leading causes of dementia and death among older adults (Centers for Disease Control and Prevention, 2013; National Institute on Aging, 2015a) and in 2010 it was estimated that 4.7 million older adults have dementia due to Alzheimer's disease (Hebert, Weuve, Scherr, \& Evans, 2013).

Driving is an important, and often primary, means of transportation for older adults. It is estimated that by 2030, one in five drivers will be over age 65 (Ortman et al., 2014). In California, there were 4.3 million people over age 65 that had driver's licenses (California Department of Motor Vehicles Forecasting Unit, 2019). While age alone does not increase safety risk for older drivers, declines in function and other age-related health issues contribute to changes in driving ability and can result in age-related driving disorders (Baird et al., 2010). In the US in 2017, older drivers accounted for $19 \%$ of all licensed drivers but also $14 \%$ of drivers involved in fatal 
collisions. In 2017 the national collision fatality rate for older adults was 13.3 per 100,000 compared to 11.0 for drivers under age 65 (National Highway Traffic Safety Administration, 2019). In California in 2017, 538 persons over age 65 were killed and 30,590 were injured in vehicle collisions. In the same year, there were 278 fatal and 14,816 injury collisions caused by older drivers over age 65 (California Highway Patrol, 2017). Drivers over age 70 are at significantly greater risk of causing fatal crashes that kill themselves compared to younger drivers (Tefft, 2008).

Cognitive impairment, including dementia and other cognitive decline resulting from neurodegenerative conditions, is a growing driving safety concern. Disorientation is a prevalent manifestation of cognitive impairment. Some older adults with mild cognitive impairment, including early-stage dementia, remain fit to drive (Frittelli et al., 2009; Lincoln, Radford, Lee, \& Reay, 2006; Uc, Rizzo, Anderson, Shi, \& Dawson, 2004; Wadley et al., 2009). However, as dementia progresses and driving ability declines, affected individuals that can no longer safely drive lose their ability to recognize their own impairment but will continue driving (Carr, Schwartzberg, Manning, \& Sempek, 2010). There is a growing body of research detailing the effect of cognitive impairment on vehicle collision risk. One landmark study found that drivers with dementia had a 2.5 times higher rate of motor vehicle crashes than expected in the general driving population and were more often found at-fault for these crashes (Cooper, Tallman, Tuokko, \& Beattie, 1993). A later study found that the odds of a collision were 10.7 times greater for drivers with dementia compared to cognitively-healthy drivers (Zuin, Ortiz, Boromei, \& Lopez, 2002).

Currently, the gold-standard for evaluating fitness-to-drive is on-road driving assessment, usually administered through each state's Department of Motor Vehicles (DMV). There is currently no standardized off-road assessment of cognitive impairment as it relates to driving ability. Several researchers have explored other assessments to evaluate fitness-to-drive including computer-based sensory-motor and cognitive tests (Hoggarth, Innes, Dalrymple-Alford, \& Jones, 2013), functional tests (Antin, Lockhart, Stanley, \& Guo, 2012), neuropsychological tests (Bliokas, Taylor, Leung, \& Deane, 2011), tests for mental illness (Eby, Molnar, Shope, \& Dellinger, 2007), and hybrid assessment batteries such as the Center for Evaluation of Fitness to Drive and Car Adaptations Assessment (Devos et al., 2013).

These assessments have many strengths such as high validity and reliability, acceptability among participants, and a wide range of measurement points from functional and physical performance to knowledge of rules of the road. However, these assessments require specific equipment, training, and time which makes their administration more challenging in licensing agency office settings. There is a need for tools to more accurately and efficiently identify and manage drivers with possible cognitive impairment. Such tools will better identify individuals that require on-road driving assessment and build a foundation for a simple instrument that can be used by driver licensing personnel. This will provide a major advantage to state licensing agencies and the field of traffic safety especially as the United States population rapidly continues to age.

\section{Current Study}

To address the need for a tool to identify potentially cognitively-impaired drivers by screening for disorientation, the Driver Orientation Screen for Cognitive Impairment (DOSCI), initially developed as part of a training curriculum for law enforcement officers, was pilot tested for licensing agency use with the Iowa Department of Transportation. The purpose of the current study was to examine the feasibility, acceptability, and usefulness of the DOSCI in a licensing agency setting and to investigate the association between DOSCI performance and driver licensing outcomes.

\section{Study Design}

\section{Methods}

The current study is a subset of the Iowa-based pilot study, including exploratory analysis of data collected between October 1, 2014 and August 1, 2015. 


\section{Developing and Validating the Driver Orientation Screen for Cognitive Impairment.}

Before the pilot study, the DOSCI was initially developed by the Training, Research and Education for Driving Safety (TREDS) program at University of California San Diego. Detailed methods for developing the DOSCI tool have been published in Hill, Rybar, Stowe, and Jahns (2016). Validation testing of the DOSCI tool was conducted in collaboration with the University of California San Diego Alzheimer's Research Center. The DOSCI tool was administered to 68 participants for validation testing. Forty-one participants had a clinical diagnosis of dementia and 27 participants were normal controls with no cognitive impairment. Independent unpaired ttests showed that the mean number of questions answered incorrectly by participants with diagnosed dementia was 2.36 ( $\mathrm{SD}=2.14)$. Mean incorrect answers by normal control participants was $0.22(\mathrm{SD}=.51 ; \mathrm{p}<.0001 ; \mathrm{Df}=66)$. The DOSCI was validated as a tool that can differentiate between cognitively-health individuals and those with dementia. The questions most frequently answered incorrectly by participants with dementia were those related to date and time (Hill, Rybar, Stowe, \& Jahns, 2016).

\section{Measures}

Intended for use by personnel outside of medical and research settings, the DOSCI tool comprised of a total of nine questions assessing orientation to place and time and memory of personal information. Scoring criteria were based on the number of questions answered incorrectly (Hill et al., 2016). For the current study, analysis was conducted using total number of incorrect responses on the DOSCI from 0-9. Another measure used for the study was eventual licensing outcome of DOSCI-screened drivers-license issued, suspended, or revoked-provided by the Iowa Department of Transportation.

\section{Iowa Pilot Study}

In 2014, TREDS collaborated with the Iowa Department of Transportation in a pilot test to train personnel from the Motor Vehicle Division (MVD) to administer the paper-based DOSCI tool verbally in-person to clients that visited any of their field offices.
Before launching the pilot study, TREDS and the Iowa DOT adapted the DOSCI scoring criteria and determined criteria for assessment, protocols for managing clients based on DOSCI score, and personnel training (Snook, 2015).The pilot study began with a trial phase during which over 500 MVD personnel were trained. The DOSCI was administered at five driver licensing stations over a month-long period. DOSCI trainings were conducted in-person, via email, and through a train-the-trainer model. In November 2014, the pilot study was expanded state-wide. Follow-up personnel training occurred after three months and email reinforcement occurred after eight months. The DOSCI assessment criteria included clients at MVD field offices with medical and vision referrals, driving re-examination referrals and appeals, and/or demonstrated confusion or difficulty answering questions. The DOSCI screen was administered in addition to MVD standard procedure, which required clients to either submit a Medical Test, complete a Drive Test, or no action was required. The DOSCI tool did not replace any standard procedure screenings. MVD personnel used the paper-based Iowa DOT Form 433100 to administer the DOSCI.

\section{Participants}

The sample for the current study included 2,510 DOSCI screens from 2,399 individuals that were assessed at Iowa MVD field offices. Ninety-nine individuals were assessed more than once throughout the duration of the pilot study as a result of administrative protocols within the Iowa licensing agency field offices. All clients were licensed drivers in the state of Iowa, fulfilled the criteria for DOSCI assessment, and answered the nine DOSCI questions.

\section{Procedures}

Feasibility and acceptance analysis of the DOSCI at the Iowa MVD were based on frequencies from the data collection form. The driver licensing outcome variable was defined as whether clients that were administered the DOSCI were issued a driver's license. Outcome was coded as "Issued" or "Not Issued." For the dichotomous pass/fail outcome of the DOSCI, a "pass" on the DOSCI was defined as $\leq 2$ incorrect responses while a 
"fail" was defined as $\geq 3$ incorrect responses. Other variables included age, gender, reason for assessment, and number of prior licensing reexaminations, vehicle crashes, and convictions. The categorical variable reason for assessment was comprised of five reasons including 1) reexamination, 2) local drive test, recall, or hearing examination, 3) line examination, 4) "other" reason, or 5) multiple reasons. If "other" reason was chosen as the reason for assessment, the DOSCI form provided space for a written description of the reason. MVD staff provided descriptions which varied from vision tests to law enforcement requests to claims of apparent client confusion.

\section{Analyses}

Univariate analysis was performed to produce descriptive statistics for all variables. Frequency calculations were performed for categorical variables while calculations of simple statistics were performed for quantitative continuous variables, including scores for Ease of Administration, Acceptance by Client, and Usefulness in Assessment. Data for these particular variables were collected from ratings by MVD staff members. Staff provided ratings on a 5-point scale for each category. A score of 1 representing "very difficult/not receptive/not useful" and a score of 5 representing "very easy/very receptive/very useful” respectively.
Bivariate analyses were conducted by Student's t-tests and Chi-square tests. Significant associations between driver licensing outcome and all continuous variables were assessed by Student's t-tests. Chi-square tests were performed to assess associations between driver licensing outcome and all categorical variables, specifically the association between driver licensing outcome and DOSCI pass/fail outcome. The Chi-square test produced an odds ratio which expressed the odds of not receiving a driver's license if a client failed the DOSCI screen. All tests were performed to a statistical significance of $\mathrm{p} \leq 0.05$.

\section{Descriptive Statistics}

\section{Results}

Average client age was 75.6 years (Table 1). Approximately $86 \%$ of the clients in the study sample were aged 60 and older and $58.5 \%$ were aged 80 and older. There were $53.2 \%(n=1275)$ males and $46.9 \%(n=1124)$ females. There was nearly even distribution between clients that were issued a driver's license $(51.7 \%, n=1034)$ and clients that were not issued a license (48.3\%, $\mathrm{n}=967$ ). The majority of the clients passed the DOSCI screen $(90.3 \%, \mathrm{n}=2267)$ while $9.7 \%$ failed $(n=243)$. The most common reason for these clients visiting the Motor Vehicle Division (MVD) office was a license re-examination (33.9\%, $n=795)$.

Table 1.

Descriptive Statistics of the Sample

\begin{tabular}{lrr}
\hline & $\mathrm{n}$ & Mean (SD) \\
\hline Age & 2,399 & $75.6(17.80)$ \\
Number of Prior Motor Vehicle Crashes & 1,423 & $0.54(0.65)$ \\
Number of Prior Convictions & 1,055 & $0.34(0.80)$ \\
Number of Prior Examinations & 1,037 & $0.24(0.58)$ \\
\hline & $\mathrm{n}$ & $\%$ \\
\hline Male & 1,275 & 53.2 \\
Female & 1,124 & 46.9 \\
DOSCI Outcome & & \\
Pass ( $\leq 2$ incorrect) & 2,267 & 90.3 \\
Fail ( $\geq 3$ incorrect) & 243 & 9.7 \\
Driver Licensing Outcome & & \\
Issued & 1,034 & 51.7 \\
Not Issued & 967 & 48.3 \\
Reason for Assessment & & 33.9 \\
Re-Examination & 795 & 11.3 \\
Local Drive Test, Recall, or Hearing Examination & 266 & 31.1 \\
Line Examination & 729 & 19.9 \\
Other Reason & 466 & 3.8 \\
Multiple Reasons & 90 & \\
\hline
\end{tabular}


The mean length of time to complete a single DOSCI assessment was 1.70 minutes ( $\mathrm{SD}=1.36$; Table 2). The mean score was $4.76(\mathrm{SD}=0.67)$ for Ease of Administration, $4.67(\mathrm{SD}=0.80)$ for Acceptance by Client, and $3.81(\mathrm{SD}=1.57)$ for Useful in Assessment (Table 2).

Table 2.

Descriptive Statistics: DOSCI Screening Administration

\begin{tabular}{lcc}
\hline Continuous Variables & $\mathrm{n}$ & Mean (SD) \\
\hline $\begin{array}{l}\text { Length of DOSCI } \\
\text { Assessment (minutes) }\end{array}$ & 2,476 & $1.70(1.36)$ \\
$\begin{array}{l}\text { Ease of Administration } \\
\text { (5-point scale) }\end{array}$ & 2,362 & $4.76(0.67)$ \\
$\begin{array}{l}\text { Acceptance by Client } \\
\text { (5-point scale) }\end{array}$ & 2,359 & $4.67(0.80)$ \\
$\begin{array}{l}\text { Useful in Assessment } \\
\text { (5-point scale) }\end{array}$ & 2,320 & $3.81(1.57)$ \\
\hline
\end{tabular}

\section{Bivariate Analyses}

Chi-square calculations showed a statistically significant relationship between driver licensing outcome and DOSCI fail outcome (Table 3). The odds of a being denied a driver's license was 2.556 times (95\% CI 1.920-3.404) greater for clients that failed the DOSCI tool. Significant relationships were also found between driver licensing outcome and older age (OR 1.010, 95\% CI 1.005-1.016), female gender (OR 1.222, 95\% CI 1.025-1.457), reason for assessment (reexamination OR 0.570, 95\% CI 0.450-0.721; local drive test, recall, or hearing examination OR 0.189, 95\% CI 0.133-0.267; other reason OR $0.496,95 \%$ CI $0.384-0.640$ ), and number of prior examinations (OR 1.350, 95\% CI 1.050-1.737; Table 3).

Table 3.

Bivariate Analysis of Driver Licensing Outcome (License Not Issued) by Variables

\begin{tabular}{|c|c|c|c|}
\hline Variable & n (\%) & OR & $95 \% \mathrm{CI}$ \\
\hline \multicolumn{4}{|l|}{ DOSCI Outcome $^{\dagger}$} \\
\hline Pass $(\leq 2$ incorrect) & $802(82.9)$ & 0.391 & $0.294-0.521$ \\
\hline Fail ( $\geq 3$ incorrect) & $165(17.1)$ & 2.556 & $1.920-3.404$ \\
\hline Number of Prior Motor Vehicle Crashes & & 1.081 & 0.907-1.289 \\
\hline Number of Prior Convictions & & 1.049 & $0.893-1.232$ \\
\hline Number of Prior Examinations ${ }^{+}$ & & 1.350 & $1.050-1.737$ \\
\hline Age $^{+}$ & & 1.010 & $1.005-1.016$ \\
\hline \multicolumn{4}{|l|}{ Gendert } \\
\hline Male & $480(49.6)$ & 0.818 & $0.686-0.975$ \\
\hline Female & $487(50.4)$ & 1.222 & $1.025-1.457$ \\
\hline \multicolumn{4}{|l|}{ Reason for Assessment } \\
\hline Re-Examination ${ }^{+}$ & $261(28.7)$ & 0.570 & $0.450-0.721$ \\
\hline Local Drive Test, Recall, or Hearing Examination ${ }^{\dagger}$ & $53(5.8)$ & 0.189 & $0.133-0.267$ \\
\hline Line Examination & $364(40.0)$ & --- & --- \\
\hline Other Reason ${ }^{\dagger}$ & $182(20.0)$ & 0.496 & $0.384-0.640$ \\
\hline Multiple Reasons & $50(5.5)$ & 1.160 & $0.706-1.906$ \\
\hline
\end{tabular}

\section{Discussion}

The purpose of this study was to explore the feasibility, acceptability, and usefulness of the DOSCI tool in a licensing agency setting and to investigate the association between pass/fail outcome of the DOSCI tool and driver licensing outcome. In this pilot study of Iowa drivers that were assessed using the DOSCI tool, feasibility, acceptability, and usefulness of the tool were ranked highly by MVD staff and pass/fail outcome was found to be related to driver licensing outcome.

California Vehicle Code (CVC) §12814(a) allows the DMV to require an on-road driving assessment for new drivers or when a driver's 
record of citations, convictions, or crashes indicates unsafe driving behavior; driving assessments based solely on age are prohibited (California Department of Motor Vehicles, 2013, 2015). Similarly to other states, to determine if an individual needs on-road assessment, California DMV relies on reports from physicians, emergency medical personnel, law enforcement, and drivers' family and friends (California Department of Motor Vehicles, 2013; Iowa Department of Transportation, 2007). Studies from various states have shown that these individuals rarely report possible driving impairment, either because they are unaware of reporting practices and mandates or are not comfortable with reporting (Cable, Reisner, Gerges, \& Thirumavalavan, 2000; Lococo, Decina, Branche, \& Wagner, 2013; Soderstrom et al., 2009). Licensing agencies often fail to identify and evaluate a potentially impaired driver until a citation or a crash occurs.

Failing the DOSCI assessment was associated with eventual license denial or suspension. The DOSCI elements involving memory and orientation agreed with the assessment recommendations for testing areas outlined by Carr et al. (2010) for assessing driving fitness in older adults. The results of the bivariate analysis aligned with previous literature testing the relationship between cognitive-based assessments and performance in on-road driving assessments, the gold standard for determining licensing status. For example, Bliokas, Taylor, Leung, and Deane (2011) investigated the association between a neuropsychological test battery and on-road driving assessment outcomes. The battery included tests on visuospatial functioning, executive functioning, attention, concentration, and memory. Their results suggested that a neuropsychological battery was effective in predicting on-road driving assessment outcomes but required further modification to improve sensitivity and specificity. A different clinical battery comprised of six cognitive tests was found to correctly identify $88 \%$ of demented drivers that had failed the on-road driving assessment (Lincoln et al., 2006) while a screening battery intended to predict on-road driving performance in individuals with Parkinson's Disease was found to correctly identify $77 \%$ of affected drivers that had failed on-road assessment (Devos, Vandenberghe, Nieuwboer, Tant, De Weerdt, Dawson, \& Uc, 2013). Since the pilot study, Iowa Department of Transportation has implemented the DOSCI as part of standard screening. Drivers that fail the DOSCI may then be referred for cognitive screening using the Safe Driving BASICS $^{\mathrm{TM}}$ standardized test battery which provides a more thorough understanding of an individual's level of impairment to assist with the decision to issue a driver's license. In California, law enforcement and emergency dispatch agencies have adopted the use of the DOSCI tool and law enforcement agencies in Tennessee are testing the DOSCI's usefulness for highway officer use.

As the number of older adult holders of California driver licenses rises and the prevalence of dementia continues to increase, there is a growing need for screening protocols in licensing agencies that assess other areas of driving impairment, especially dementia and other cognitive decline. Screening tools should be quick and easy to administer, easily incorporated into current licensing process, and not create extra burden on staff, resources, and clients. The DOSCI is a screening tool for disorientation to person, place and time and highly correlated with dementia that was found to be useful by licensing agency staff, easy to use, and well-accepted by clients. These results are in agreement with results measured from the California law enforcement officers that were trained to use the DOSCI tool during a roadside stop. The majority of officers found the DOSCI tool useful and were likely to incorporate the tool into their regular roadside assessment practices (Rigdon, Atkinson, Bosack, O'Donnell, \& Lambert, 2014). Adding the DOSCI tool to regular licensing renewal screening processes may provide a valuable means to better identify potentially impaired drivers deserving of closer examination. In high population density states like California, such a tool can help alleviate the burden of collisions and injuries on the roadways and better safeguard the aging population by connecting impaired individuals with the evaluation and resources needed to keep them mobile or consider driving retirement as necessary. 


\section{Limitations}

The primary limitation of this study was the prevalence of missing data for the dependent variable, driver licensing outcome, due to errors or non-compliance from personnel that administered the DOSCI tool. This may have skewed the data for the dependent variable and misrepresented the relationship between driver licensing outcome and DOSCI pass/fail outcome. To improve data quality, future researchers may attempt to exercise better oversight over personnel administering the DOSCI tool by focusing on a smaller geographic region or a single field office. A second limitation was that the DOSCI screening tool operated on the assumption that cognitive impairment is the sole explanation for a failing score on the assessment. However, there are other individual-level factors that may have influenced DOSCI outcome including test anxiety, feelings of intimidation in the presence of law enforcement or MVD personnel, or fear of driver's license revocation. There also may have been other medical explanations for apparent memory loss besides cognitive impairment or neurodegenerative disease including malnutrition, dehydration, depression, uncontrolled diabetes, medication side-effects, or thyroid, kidney, or liver conditions (National Institute on Aging, 2015b). These possible alternative explanations may have influenced DOSCI performance and impacted the relationship between driver licensing and DOSCI outcome. Future research may benefit from measuring individual-level factors such as client stress to investigate any possible impact on either DOSCI performance or driver licensing outcome.

\section{Conclusion}

The use of the DOSCI in a licensing agency setting was rated as feasible, acceptable, and useful. In addition, DOSCI performance was associated with driver licensing outcome. Clients that failed the DOSCI assessment had significantly higher odds of not receiving a driver's license than clients that passed. This provides preliminary evidence of the DOSCI tool's effectiveness as a first step in identifying individuals that are no longer fit to drive due to probable disorientation and predicting their eventual licensing status.

Identifying at-risk individuals as early as possible will assist licensing agencies to provide the proper in-depth assessments, such as standardized tests of cognitive function and, in some cases, a behind-the-wheel examination, at the appropriate time in an individual's driving career. The ability to quickly identify impaired individuals before they experience any adverse incidents on the roadway will help extend the reach of resources required to serve a growing older adult population and ultimately improve traffic safety.

\section{References}

Antin, J. F., Lockhart, T. E., Stanley, L. M., \& Guo, F. (2012). Comparing the impairment profiles of older drivers and non-drivers: Toward the development of a fitness-to-drive model. Safety Science, 50(2), 333-341. https://doi.org/10.1016/j.ssci.2011.09.013

Baird, S., Hill, L., Rybar, J., Concha-Garcia, S., Coimbra, R., \& Patrick, K. (2010). Age-related driving disorders: Screening in hospitals and outpatients settings. Geriatrics \& Gerontology International, 10(4), 288-294. https://doi.org/10.1111/j.1447-0594.2010.00622.x

Bliokas, V. V, Taylor, J. E., Leung, J., \& Deane, F. P. (2011). Neuropsychological assessment of fitness to drive following acquired cognitive impairment. Brain Injury, 25(5), 471-487. https://doi.org/10.3109/02699052.2011.559609

Cable, G., Reisner, M., Gerges, S., \& Thirumavalavan, V. (2000). Knowledge, attitudes, and practices of geriatricians regarding patients with dementia who are potentially dangerous automobile drivers: A national survey. Journal of the American Geriatrics Society, 48(1), 14-17. https://doi.org/10.1111/j.1532-5415.2000.tb03022.x

California Department of Motor Vehicles. (2013). Fast facts: A general guide for drivers required to appear for a reexamination. Retrieved January 27, 2016, from 
http://www.dmv.ca.gov/portal/dmv/?1dmy\&urile=wcm:path:/dmv_content_en/dmv/pubs/brochur es/fast_facts/ffdl27

California Department of Motor Vehicles. (2015). DMV senior guide for safe driving. DL 625. Sacramento, Ca. Retrieved from http://www.dmv.ca.gov/portal/wcm/connect/8a431ac8-535b4783-b006-a6c6cf58ef18/dl625senior.pdf?MOD=AJPERES

California Department of Motor Vehicles Forecasting Unit. (2019). Department of Motor Vehicles estimated licenses outstanding by age and gender as of December 31, 2018. Sacramento, CA.

California Highway Patrol. (2017). Statewide Integrated Traffic Records System (SWITRS) collision data FFYS Oct 2016-Sept 2017. Sacramento, CA.

Carr, D. B., Schwartzberg, J. G., Manning, L., \& Sempek, J. (2010). Physician's guide to assessing and counseling older drivers. DOT HS 811298 (2nd ed.). Washington, DC: National Highway Traffic Safety Administration. Retrieved from www.nhtsa.gov/staticfiles/nti/older_drivers/pdf/811298.pdf

Centers for Disease Control and Prevention. (2013). The state of aging and health in America 2013. Atlanta, GA. Retrieved from www.cdc.gov/aging

Congdon, N., O’Colmain, B., Klaver, C. C., Klein, R., Muñoz, B., Friedman, D. S., ... Mitchell, P. (2004). Causes and prevalence of visual impairment among adults in the United States. Archives of Ophthalmology, 122(4), 477-485. https://doi.org/10.1001/archopht.122.4.477

Cooper, P. J., Tallman, K., Tuokko, H., \& Beattie, B. L. (1993). Vehicle crash involvement and cognitive deficit in older drivers. Journal of Safety Research, 24(1), 9-17. https://doi.org/10.1016/00224375(93)90047-Q

Devos, H., Vandenberghe, W., Nieuwboer, A., Tant, M., De Weerdt, W., Dawson, J. D., \& Uc, E. Y. (2013). Validation of a screening battery to predict driving fitness in people with Parkinson's disease. Movement Disorders, 28(5), 671-674. https://doi.org/10.1002/mds.25387

Eby, D. W., Molnar, L. J., Shope, J. T., \& Dellinger, A. M. (2007). Development and pilot testing of an assessment battery for older drivers. Journal of Safety Research, 38(5), 535-543. https://doi.org/10.1016/j.jsr.2007.07.004

Frittelli, C., Borghetti, D., Iudice, G., Bonanni, E., Maestri, M., Tognoni, G., ... Iudice, A. (2009). Effects of Alzheimer's disease and mild cognitive impairment on driving ability: A controlled clinical study by simulated driving test. International Journal of Geriatric Psychiatry, 24(3), 232-238. https://doi.org/10.1002/gps.2095

Hebert, L. E., Weuve, J., Scherr, P. A., \& Evans, D. A. (2013). Alzheimer disease in the United States (2010-2050) estimated using the 2010 census. Neurology, 80(19), 1778-1783. https://doi.org/10.1212/WNL.0b013e31828726f5

Hill, L. L., Rybar, J., Stowe, J., \& Jahns, J. (2016). Development of a curriculum and roadside screening tool for law enforcement identification of medical impairment in aging drivers. Injury Epidemiology, 3(13), 1-9. https://doi.org/10.1186/s40621-016-0078-3

Hoggarth, P. A., Innes, C. R. H., Dalrymple-Alford, J. C., \& Jones, R. D. (2013). Prospective study of healthy older drivers: No increase in crash involvement or traffic citations at 24 months following a failed on-road assessment. Transportation Research Part F, 16, 73-80. https://doi.org/10.1016/j.trf.2012.08.012

Iowa Department of Transportation. (2007). Driving with diminished skills: Driving with normal aging changes and driving with dementia or Alzheimer's disease. Retrieved from http://publications.iowa.gov/11753/1/diminishedskills.pdf

Lincoln, N. B., Radford, K. A., Lee, E., \& Reay, A. C. (2006). The assessment of fitness to drive in people with dementia. International Journal of Geriatric Psychiatry, 21(11), 1044-1051. https://doi.org/10.1002/gps.1604

Lindsay, J., Sykes, E., McDowell, I., Verreault, R., \& Laurin, D. (2004). More than the epidemiology of Alzheimer's disease: Contributions of the Canadian Study of Health and Aging. Canadian Journal of Psychiatry, 49(2), 83-92. 
Lococo, K. H., Decina, L. E., Branche, J., \& Wagner, E. M. (2013). Medical review process and license disposition of drivers referred by law enforcement in Virginia. Journal of Safety Research, 45, 47-53. https://doi.org/10.1016/j.jsr.2013.01.005

National Highway Traffic Safety Administration. (2019). Older population: 2017 data. Washington, DC. Retrieved from http://www-nrd.nhtsa.dot.gov/Pubs/809778.pdf

National Institute on Deafness and Other Communication Disorders. (2015). Quick statistics. National Institute on Deafness and Other Communication Disorders (NIDCD). Retrieved from http://www.nidcd.nih.gov/health/statistics/Pages/quick.aspx\#5

Ortman, J. M., Velkoff, V. A., \& Hogan, H. (2014). An aging nation: The older population in the United States. Current Population Reports, P25-1140. Washington, DC. Retrieved from census.gov

Snook, K. (2015). Screening drivers for cognitive impairment at a state licensing agency. In American Association of Motor Vehicle Administrators Annual International Conference. Des Moines, IA.

Soderstrom, C. A., Scottino, M. A., Joyce, J. J., Burch, C., Ho, S. M., \& Kerns, T. J. (2009). Police referral of drivers to the Maryland Motor Vehicle Administration's Medical Advisory Board. Annals of Advances in Automotive Medicine, 53, 105-116. Retrieved from http://www.ncbi.nlm.nih.gov/pubmed/20184837

Tefft, B. C. (2008). Risks older drivers pose to themselves and to other road users. Journal of Safety Research, 39(6), 577-582. https://doi.org/10.1016/j.jsr.2008.10.002

Uc, E., Rizzo, M., Anderson, S., Shi, Q., \& Dawson, J. (2004). Driver route-following and safety errors in early Alzheimer disease. Neurology, 63(5), 832-837. https://doi.org/10.1212/01.WNL.0000139301.01177.35

Wadley, V. G., Okonkwo, O., Crowe, M., Vance, D. E., Elgin, J. M., Ball, K. K., \& Owsley, C. (2009). Mild cognitive impairment and everyday function: An investigation of driving performance. Journal of Geriatric Psychiatry and Neurology, 22(2), 87-94. https://doi.org/10.1177/0891988708328215

Zuin, D., Ortiz, H., Boromei, D., \& Lopez, O. L. (2002). Motor vehicle crashes and abnormal driving behaviours in patients with dementia in Mendoza, Argentina. European Journal of Neurology, 9(1), 29-34. Retrieved from http://www.ncbi.nlm.nih.gov/pubmed/11784373

Author Information

Sarah Andrade

Department of Family Medicine and Public Health

University of California, San Diego

9500 Gilman Drive, \#0811

La Jolla, CA 92093-0811

Telephone: 858-534-8386

Email: s1andrade@ucsd.edu 